\title{
Variations in the Efficiency of Albuterol Delivery and Intrapulmonary Effects With Differential Parameter Settings on Intrapulmonary Percussive Ventilation
}

\author{
Takashi Karashima, Yuka Mimura-Kimura, Kanade Miyakawa, Akihiro Nakamura, \\ Fuminori Shimahara, Haruhito Kamei, and Yusuke Mimura
}

\begin{abstract}
BACKGROUND: Intrapulmonary percussive ventilation (IPV) is used for airway clearance and delivery of aerosol medications, including bronchodilators. Despite the common use of IPV for drug delivery, few data are available regarding optimization of inhalation therapy with IPV. In this study, we investigated the influence of IPV setting parameters and lung mechanics on drug delivery via IPV alone. METHODS: An IPV device was connected to a lung model via a trachea model and a flow analyzer. Albuterol nebulized from the IPV device was collected onto a filter attached between the trachea and lung models, and was quantitated by spectrophotometry $(230 \mathrm{~nm})$. RESULTS: Albuterol delivery to the lung model was increased up to 2.1-fold, with decreasing percussion frequency. Decreasing percussion frequency concomitantly increased the tidal volume, and albuterol delivery was correlated with tidal volume $(r=0.91, P<.001)$. Airway resistance had a negative impact on albuterol delivery, whereas lung compliance had no significant effect. Increasing operational pressure increased albuterol delivery while increasing peak inspiratory pressure. CONCLUSIONS: Albuterol delivery and tidal volume with IPV can be improved by maintaining low levels of percussion frequency and increasing operational pressure. When increasing operational pressure, the peak inspiratory pressure and airway resistance levels need to be carefully monitored for safe inhalation therapy with IPV. Key words: intrapulmonary percussive ventilation; albuterol; drug delivery. [Respir Care 2019;64(5):502-508. () 2019 Daedalus Enterprises]
\end{abstract}

\section{Introduction}

Intrapulmonary percussive ventilation (IPV) is high-frequency percussive ventilation that delivers small bursts of gas into the lungs for airway clearance. ${ }^{1}$ IPV can provide both ventilation and delivery of nebulized drugs simultaneously by its unique ventilation system. ${ }^{2}$ IPV is used in both children and adults for various diseases, including COPD, ${ }^{3-6}$ Duch-

\footnotetext{
Mr Karashima, Ms Miyakawa, Mr Nakamura, and Mr Shimahara are affiliated with the Department of Medical Engineering, National Hospital Organization Yamaguchi-Ube Medical Center, Ube, Japan. Mr Karashima, Ms Mimura-Kimura, Dr Kamei, and Dr Mimura are affiliated with the Department of Clinical Research, National Hospital Organization Yamaguchi-Ube Medical Center, Ube, Japan.

The authors have disclosed no conflicts of interest.

Supplementary material related to this paper is available at http:// www.rcjournal.com.
}

enne muscular dystrophy, ${ }^{7}$ bronchiectasis, ${ }^{8}$ and cystic fibrosis. ${ }^{9,10}$ Therefore, IPV treatments need to be tailored for individual patients with differing respiratory conditions and clinical states. Although some intrapulmonary effects of setting parameters in IPV devices have been reported,,${ }^{11}$ it remains unknown how IPV parameters should be configured for optimal drug delivery in patients with different lung mechanics, including compliance (lung compliance $\left[\mathrm{C}_{\mathrm{L}}\right]$ ) and airway resistance $\left(\mathrm{R}_{\mathrm{aw}}\right)$. Previously, drug delivery with IPV has only been investigated at a constant pressure and frequency ${ }^{12}$ or in a mechanical ventilator circuit. ${ }^{13}$ In clinical practice, however, drug delivery can be performed via IPV

\footnotetext{
Correspondence: Yusuke Mimura MD, Department of Clinical Research, National Hospital Organization Yamaguchi-Ube Medical Center, $685 \mathrm{Hi}-$ gashi-Kiwa, Ube, 755-0241 Japan.
}

DOI: $10.4187 /$ respcare. 06348 
alone in patients without spontaneous breathing, ${ }^{14,15}$ and drug delivery optimization is not well understood.

\section{See the Related Editorial on Page 612}

In this study, we investigated the impact of alterations in the settings of the parameters of IPV (frequency and operational pressure) and lung mechanics $\left(\mathrm{C}_{\mathrm{L}}\right.$ and $\left.\mathrm{R}_{\mathrm{aw}}\right)$ on the efficiency of drug delivery and intrapulmonary effects. This in vitro study simulated the situation of patients on mechanical ventilation who received nebulized medication via IPV alone, with mechanical ventilation being withheld during IPV. Increased drug delivery and concomitant changes in the intrapulmonary effects with differing IPV parameter settings and lung mechanics provide insights into improved aerosol inhalation therapy with IPV in patients without spontaneous breathing.

\section{Methods}

\section{Nebulization of Albuterol With IPV}

An IPV device (IPV-1C, A50007-1, A50010-3, Percussionaire, Sandpoint, Idaho) was connected to a trachea model (condenser tube, $20 \mathrm{~mm} \times 30 \mathrm{~cm}$, Percussionaire), FlowAnalyser (PF-300, IMT Medical, Buchs, Switzerland), and a lung model (Model 1600, Dual Adult TTL, Michigan Instruments, Grand Rapids, Michigan) (Fig. 1). A

A

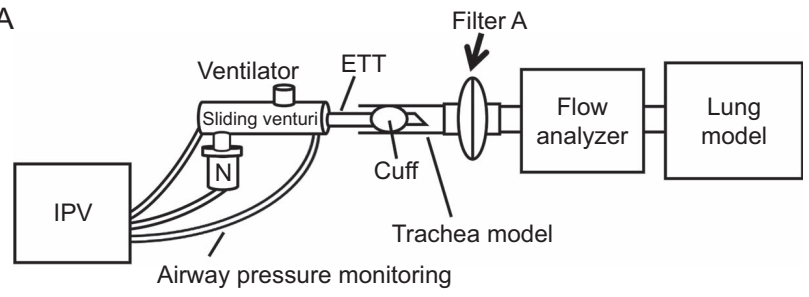

B

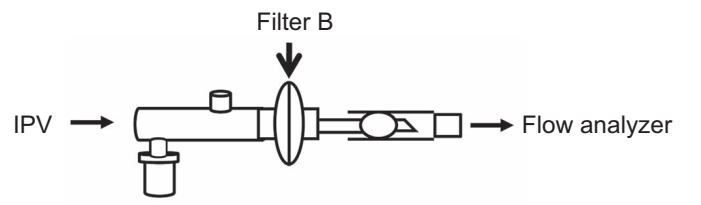

C

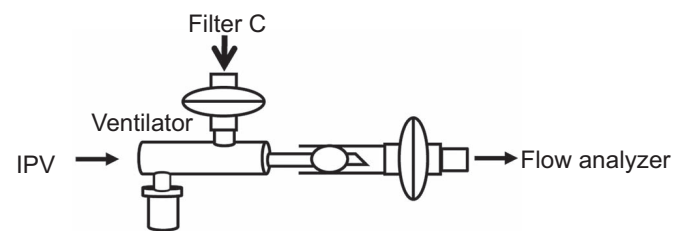

Fig. 1. Diagram of experimental setup for albuterol delivery with intrapulmonary percussive ventilation (IPV) and the positions of the filters for collection of albuterol. A: At the distal end of the trachea model. B: At the proximal end of the ETT. C: At the ventilator. $\mathrm{ETT}=$ endotracheal tube, $\mathrm{N}=$ nebulizer.

\section{QUICK LOOK}

\section{Current knowledge}

Albuterol can be delivered via intrapulmonary percussive ventilation (IPV) in both patients who are spontaneously breathing and patients on mechanical ventilation. However, variations in the efficiency of drug delivery with differing IPV parameter settings and lung mechanics may impact patient response.

\section{What this paper contributes to our knowledge}

Albuterol delivery via IPV was increased with decreasing frequency and increasing operational pressure but was decreased at high airway resistance, irrespective of lung compliance. These IPV settings that improved albuterol delivery concomitantly increased tidal volume. Because peak inspiratory pressure markedly increased with increasing operational pressure at high airway resistance, careful monitoring is important to avoid lung injury.

cuffed endotracheal tube (ETT) $(8.0 \mathrm{~mm} \times 36 \mathrm{~cm})(\mathrm{Ta}-$ perGuard, Medtronic, Dublin, Ireland) was placed to connect the sliding venturi (Percussionaire) to the trachea model with $25 \mathrm{~cm} \mathrm{H}_{2} \mathrm{O}$ of cuff pressure (Fig. 1). One $\mathrm{mL}$ of albuterol solution $(0.5 \%$ Ventolin, GlaxoSmithKline, London, United Kingdom) was diluted with $10 \mathrm{~mL}$ of saline solution and nebulized from the IPV device toward the lung model for $15 \mathrm{~min}$.

Configuration parameters of the IPV device were 20 or 40 psi of operational pressure and fully "easy" or "hard" mode of percussion. The easy and hard percussion settings correspond to frequencies of 300 and 100 cycles/min, respectively. The pulse/interval ratio setting was 1:2.5. The conditions of the lung model used were 20 or $100 \mathrm{~mL} / \mathrm{cm} \mathrm{H}_{2} \mathrm{O}$ of $\mathrm{C}_{\mathrm{L}}$ and 5 or $50 \mathrm{~cm} \mathrm{H}_{2} \mathrm{O} / \mathrm{L} / \mathrm{s}$ of $\mathrm{R}_{\mathrm{aw}}$. A filter in a cartridge housing (Inspiratory/Expiratory Breathing Circuit Filters, RT019, Fisher and Paykel, Auckland, New Zealand) to capture albuterol was placed between the trachea model and the FlowAnalyser, separated from the tip of the ETT by $2 \mathrm{~cm}$ (Filter A) (Fig. 1). The FlowAnalyser measured peak inspiratory flow, peak expiratory flow, PEEP, peak inspiratory pressure (PIP), and tidal volume $\left(\mathrm{V}_{\mathrm{T}}\right)$. These intrapulmonary effects were measured in triplicate $1 \mathrm{~min}$ after the start of IPV. To examine any deposition of albuterol outside the lung model, 2 additional filters were attached at the proximal end of the ETT (Filter B) and the ventilator of the sliding venturi (Filter C) (Fig. 1).

\section{Measurement of Albuterol}

All the albuterol solution was completely nebulized from the IPV device within $15 \mathrm{~min}$ of operation, and the filter 
cartridge was immediately removed from the circuit. The filter was immersed in $2 \mathrm{~mL}$ of $100 \%$ ethanol in a $15-\mathrm{mL}$ Falcon tube (Corning, Corning, New York) and centrifuged at $200 \mathrm{~g}$ for $10 \mathrm{~min}$ after elution with agitation for $2-3 \mathrm{~h}$. The albuterol concentration $(\mu \mathrm{g} / \mathrm{mL})$ was determined at $230 \mathrm{~nm}$ with an ND-100 spectrophotometer (NanoDrop Technologies, Wilmington, Delaware) ${ }^{13,16}$ by using a standard curve of albuterol dissolved in ethanol. The minimum measurable concentration was $8 \mu \mathrm{g} / \mathrm{mL}$. The efficiency of albuterol delivery was estimated as the following: percentage efficiency $=$ (the amount of albuterol captured in a filter $[\mu \mathrm{g}] / 5,000) \times 100$.

\section{Rationale for Parameter Settings of the Lung Model}

The $\mathrm{R}_{\mathrm{aw}}$ and $\mathrm{C}_{\mathrm{L}}$ values of healthy individuals are $<5 \mathrm{~cm}$ $\mathrm{H}_{2} \mathrm{O} / \mathrm{L} / \mathrm{s}$ and $>80 \mathrm{~mL} / \mathrm{cm} \mathrm{H}_{2} \mathrm{O}$, respectively. ${ }^{17,18}$ In 24 subjects on ventilation and with pulmonary edema and chronic airway obstruction, $\mathrm{R}_{\mathrm{aw}}$ ranged from $8.0 \pm 4.6$ to $26.4 \pm 13.4 \mathrm{~cm}$ $\mathrm{H}_{2} \mathrm{O} / \mathrm{L} / \mathrm{s}$ and $\mathrm{C}_{\mathrm{L}}$ was from $35 \pm 5$ to $66 \pm 20 \mathrm{~mL} / \mathrm{cm} \mathrm{H}_{2} \mathrm{O}$ on day 1 from the onset of mechanical ventilation, and there was a subject who showed $>50 \mathrm{~cm} \mathrm{H}_{2} \mathrm{O} / \mathrm{L} / \mathrm{s}$ of $\mathrm{R}_{\mathrm{aw}}$ due to obstructive lung disease. ${ }^{19}$ Another in vivo study showed that 13 subjects on ventilation and with acute lung injury had 7.2-17.2 $\mathrm{cm} \mathrm{H}_{2} \mathrm{O} / \mathrm{L} / \mathrm{s}$ of $\mathrm{R}_{\mathrm{aw}}$ and $26.3-102 \mathrm{~mL} / \mathrm{cm} \mathrm{H}_{2} \mathrm{O}$ of $\mathrm{C}_{\mathrm{L}} \cdot{ }^{20}$ Hence, we mimicked these subjects on ventilation and with target symptoms for IPV therapy and configured the parameters of the lung model. The normal pulmonary conditions to simulate healthy lungs were $5 \mathrm{~cm} \mathrm{H}_{2} \mathrm{O} / \mathrm{L} / \mathrm{s}$ of $\mathrm{R}_{\mathrm{aw}}$ and $100 \mathrm{~mL} / \mathrm{cm} \mathrm{H}_{2} \mathrm{O}$ of $\mathrm{C}_{\mathrm{L}}$, whereas diseased pulmonary conditions $50 \mathrm{~cm} \mathrm{H}_{2} \mathrm{O} / \mathrm{L} / \mathrm{s}$ of $\mathrm{R}_{\mathrm{aw}}$ and/or $20 \mathrm{~mL} / \mathrm{cm} \mathrm{H}_{2} \mathrm{O}$ of $\mathrm{C}_{\mathrm{L}}$.

\section{Statistical Analysis}

Parameters were set in 16 combinations of frequency (easy vs hard mode) and operational pressure (20 vs 40 psi) in the IPV device, and $\mathrm{C}_{\mathrm{L}}\left(20 \mathrm{vs} 100 \mathrm{~cm} \mathrm{H}_{2} \mathrm{O} / \mathrm{mL}\right)$ and $\mathrm{R}_{\text {aw }}$ (5 vs $50 \mathrm{~cm} \mathrm{H}_{2} \mathrm{O} / \mathrm{L} / \mathrm{s}$ ) in the lung model. The amounts of albuterol deposited onto filters were measured in triplicate in these 16 combinations, and the 2-tailed Wilcoxon signed-rank test was performed to assess whether the amounts of albuterol delivered were changed between 2 different settings of each parameter. The correlation between $\mathrm{V}_{\mathrm{T}}$ and the amounts of albuterol deposited onto filters was evaluated by the Pearson product-moment correlation coefficient. All statistical analyses were conducted by using SPSS version 25.0 (IBM, Armonk, New York), and $P$ values $<.05$ were considered statistically significant.

\section{Results}

Albuterol delivery and intrapulmonary effects in 16 combinations of frequency and operational pressure in the IPV device and $R_{a w}$ and $C_{L}$ in the lung model were determined as follows.

\section{Albuterol Delivery Via IPV}

The amounts of albuterol in the eluates of the filters (Filter A) (Fig. 1) ranged from 23.7 to $102 \mu \mathrm{g}$ (Fig. 2), which corresponded to $0.5-2.0 \%$ of the initial dose $(5 \mathrm{mg}$ ) of albuterol nebulized from the IPV device. The parameters that achieved the maximum albuterol delivery were $40 \mathrm{psi}$ of operational pressure and the hard mode of percussion under the normal pulmonary conditions of the lung model, that is, $5 \mathrm{~cm} \mathrm{H} \mathrm{H}_{2} \mathrm{O} / \mathrm{L} / \mathrm{s}$ of $\mathrm{R}_{\text {aw }}$ and $100 \mathrm{~mL} / \mathrm{cm} \mathrm{H}_{2} \mathrm{O}$ of $\mathrm{C}_{\mathrm{L}}$. In contrast, the lowest albuterol delivery was observed at $20 \mathrm{psi}$, easy mode, and $50 \mathrm{~cm} \mathrm{H}_{2} \mathrm{O} / \mathrm{L} / \mathrm{s}$ of $\mathrm{R}_{\mathrm{aw}}$, irrespective of $\mathrm{C}_{\mathrm{L}}$ (Fig. 2D). Under the normal pulmonary conditions, $140 \mu \mathrm{g}$ of albuterol (2.8\% of the initial dose) was captured at proximal end of the ETT (Filter B) (Fig. 1) and $760.8 \mu \mathrm{g}(15.2 \%$ of the initial dose) at the ventilator of the sliding venturi (Filter C) (Fig. 1). Therefore, these results indicated that the amounts of albuterol delivered to the ETT by the intake flow were $\sim 5$ times lower than that removed from the ventilator by the counterflow.

\section{Intrapulmonary Effects}

$\mathbf{V}_{\mathbf{T}} \cdot \mathrm{V}_{\mathrm{T}}$ ranged from 27 to $341 \mathrm{~mL}$. As previously reported, ${ }^{11}$ increasing operational pressure and decreasing frequencies increased $V_{T}$ (Fig. 3A). $V_{T}$ was also increased with decreasing $R_{a w}$, irrespective of $C_{L}$. $V_{T}$ was $>200 \mathrm{~mL}$ at the hard mode and $5 \mathrm{~cm} \mathrm{H}_{2} \mathrm{O} / \mathrm{L} / \mathrm{s}$ of $\mathrm{R}_{\mathrm{aw}}$, even at $20 \mathrm{psi}$ of operational pressure. The largest $\mathrm{V}_{\mathrm{T}}$ value was observed at the hard mode, $40 \mathrm{psi}$ of operational pressure and $5 \mathrm{~cm} \mathrm{H}_{2} \mathrm{O} / \mathrm{L} / \mathrm{s}$ of $\mathrm{R}_{\mathrm{aw}}$, whereas the lowest $\mathrm{V}_{\mathrm{T}}$ value was at the easy mode, 20 psi of operational pressure and $50 \mathrm{~cm} \mathrm{H}_{2} \mathrm{O} / \mathrm{L} / \mathrm{s}$ of $\mathrm{R}_{\mathrm{aw}}$.

PIP. PIP ranged from 15.6 to $95.8 \mathrm{~cm} \mathrm{H}_{2} \mathrm{O}$ (Fig. 3B). PIP was increased with increasing operational pressure and $\mathrm{R}_{\mathrm{aw}}$, irrespective of $\mathrm{C}_{\mathrm{L}}$, and was shown to be $>30 \mathrm{~cm} \mathrm{H}_{2} \mathrm{O}$ at $50 \mathrm{~cm} \mathrm{H}_{2} \mathrm{O} / \mathrm{L} / \mathrm{s}$ of $\mathrm{R}_{\mathrm{aw}}$. The frequency had a marginal effect on PIP. The lowest PIP value was observed at 20 psi of operational pressure under normal pulmonary conditions. The highest PIP value was at the hard mode, $40 \mathrm{psi}$ of operational pressure and $50 \mathrm{~cm}$ $\mathrm{H}_{2} \mathrm{O} / \mathrm{L} / \mathrm{s}$ of $\mathrm{R}_{\mathrm{aw}}$.

PEEP. PEEP ranged from 2.2 to $10.9 \mathrm{~cm} \mathrm{H}_{2} \mathrm{O}$ (Fig. 3C). PEEP was increased with the easy mode and increased operational pressure. The highest PEEP value was at the easy mode and $40 \mathrm{psi}$ of operational pressure under the normal pulmonary conditions. The lowest PEEP value was at the hard mode, $20 \mathrm{psi}$ of operational pressure and $50 \mathrm{~cm} \mathrm{H}_{2} \mathrm{O} / \mathrm{L} / \mathrm{s}$ of $\mathrm{R}_{\mathrm{aw}}$ and $100 \mathrm{~mL} / \mathrm{cm} \mathrm{H}_{2} \mathrm{O}$ of $\mathrm{C}_{\mathrm{L}}$. 

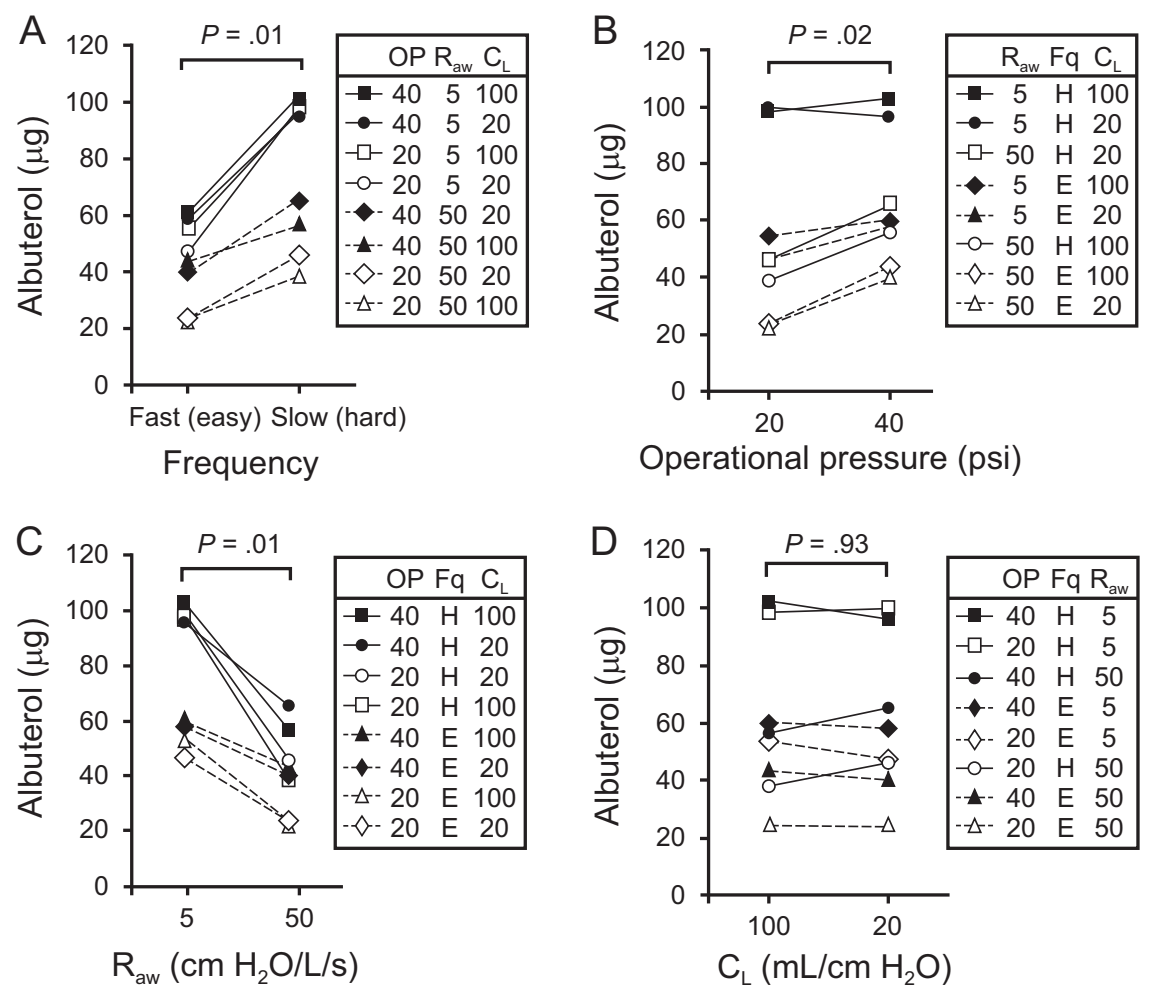

Fig. 2. Effect of intrapulmonary percussive ventilation (IPV) parameters and lung mechanics on albuterol delivery. The amounts of albuterol were compared between 2 different conditions of each parameter by using the 2-tailed Wilcoxon signed-rank test. A: Frequency (easy or hard). B: Operational pressure (20 or 40 psi). C: Airway resistance $\left(R_{a w}\right)\left(5\right.$ or $\left.50 \mathrm{~cm} \mathrm{H}_{2} \mathrm{O} / \mathrm{L} / \mathrm{s}\right)$. D: Lung compliance $\left(\mathrm{C}_{\mathrm{L}}\right)(20 \mathrm{or} 100 \mathrm{~mL} / \mathrm{cm}$ $\mathrm{H}_{2} \mathrm{O}$ ).

Peak Inspiratory Flow. The highest positive value of pulse flow during inspiration (see supplementary Fig. 1 at http://www.rcjournal.com), peak inspiratory flow, ranged from 34.8 to $131.0 \mathrm{~L} / \mathrm{min}$ (Fig. 3D). Peak inspiratory flow was increased with increasing operational pressure and decreasing $\mathrm{R}_{\mathrm{aw}}$, irrespective of $\mathrm{C}_{\mathrm{L}}$. The maximum peak inspiratory flow was observed at the hard mode and $40 \mathrm{psi}$ of operational pressure under the normal pulmonary conditions. The minimum levels were at the easy mode, $20 \mathrm{psi}$ of operational pressure and $50 \mathrm{~cm} \mathrm{H}_{2} \mathrm{O} / \mathrm{L} / \mathrm{s}$ of $\mathrm{R}_{\mathrm{aw}}$.

Peak Expiratory Flow. The lowest negative value of pulse flow (supplementary Fig. 1 at http://www.rcjournal.com), peak expiratory flow, ranged from -68.3 to $-17.6 \mathrm{~L} / \mathrm{min}$ (Fig. 3E). The extent of the peak expiratory flow was increased with increasing operational pressure and decreasing $R_{a w}$, as observed for peak inspiratory flow (Fig. 3D).

\section{Discussion}

Drug delivery via IPV is commonly performed in patients on mechanical ventilation, although the influence of IPV setting parameters on drug delivery has not been well understood. It also remains unclear how differing lung mechanics influence the efficacy of the IPV treatment. To our knowledge, this study was the first to show variations in the efficiency of drug delivery and intrapulmonary effects with differential IPV parameter settings and lung mechanics.

The maximum amount of albuterol $(\sim 100 \mu \mathrm{g}, 2 \%$ of the initial dose) was delivered at the hard mode of frequency $(\sim 100$ cycles/min) under the normal pulmonary conditions of the lung model, which was $\sim 2$ times greater than that at the easy mode $(\sim 300$ cycles/min). With decreasing frequency from the easy to hard mode, the entrainment of gas from the nebulizer by the sliding venturi improved, which accounted for the increase in albuterol delivery (Fig. 2A) and $\mathrm{V}_{\mathrm{T}}$ (Fig. 3A; supplementary Fig. 2 at http://www.rcjournal.com). The relationship of $\mathrm{V}_{\mathrm{T}}$ with frequency was consistent with the Toussaint et al study. ${ }^{11}$ Increasing operational pressure also increased albuterol delivery (Fig. 2B). Interestingly, $C_{L}$ was found to have no significant impact on albuterol delivery (Fig. 2D). It was likely that the lack of influence of $C_{L}$ was attributed to minibursts of air delivered by IPV with high frequency. The IPV-treated airways can be held inflated by the high-frequency gas pulse. ${ }^{3,4}$ By contrast, increased $R_{a w}$ had a negative impact on albuterol delivery (Fig. 2C). 

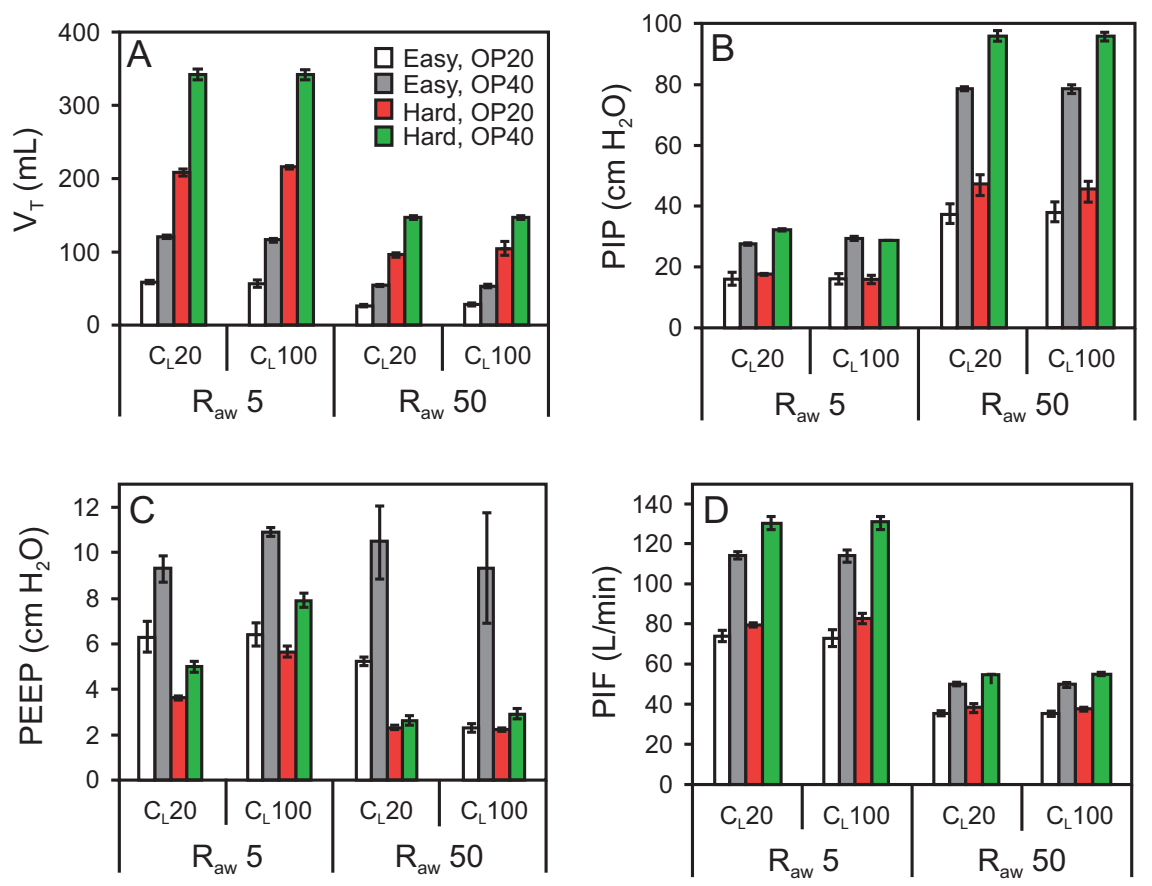

Lung model setting

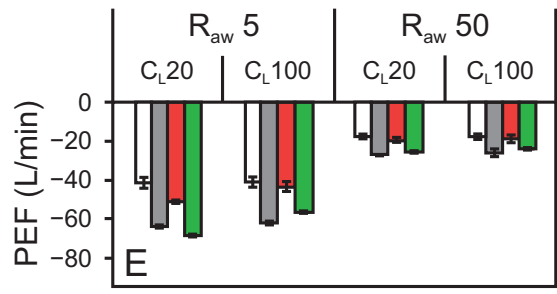

Fig. 3. Intrapulmonary effects of intrapulmonary percussive ventilation (IPV) parameters and lung mechanics. A: Tidal volume $\left(V_{T}\right)$. B: Peak inspiratory pressure (PIP). C: PEEP. D: Peak inspiratory flow (PIF). E: Peak expiratory flow (PEF). OP = operational pressure (20 or 40 psi); $R_{\text {aw }}=$ airway resistance ( 5 or $\left.50 \mathrm{~cm} \mathrm{H}_{2} \mathrm{O} / \mathrm{L} / \mathrm{s}\right) ; \mathrm{C}_{\mathrm{L}}=$ lung compliance $\left(20\right.$ or $\left.100 \mathrm{~mL} / \mathrm{cm} \mathrm{H}_{2} \mathrm{O}\right)$. The error bars represent SD of 3 independent experiments.

The decrease in albuterol delivery at high $\mathrm{R}_{\mathrm{aw}}$ was related to a decrease in the quantity of gas entrained by the venturi as a result of the increased downstream resistance. The same is true for the decrease in $V_{T}$ with increasing $R_{a w}$ (see supplementary Fig. 3 at http://www.rcjournal.com).

The maximum albuterol delivery was observed when $\mathrm{V}_{\mathrm{T}}$ was $>200 \mathrm{~mL}$ (Fig. 4). It should be noted that albuterol delivery correlated with $\mathrm{V}_{\mathrm{T}}$ during IPV $(\mathrm{r}=0.91, P<.001)$ (Fig. 4). Previously, the impact of $\mathrm{V}_{\mathrm{T}}$ on drug delivery has been reported as both positive and neutral by using jet nebulizers, a pressurized metered-dose inhaler, and IPV.13,21-25 O'Riordan et al, ${ }^{25}$ when using 4 types of jet nebulizers, reported that increasing $\mathrm{V}_{\mathrm{T}}$ from 700 to $1,000 \mathrm{~mL}$ resulted in up to a $25 \%$ increase in drug delivery. Fink et $\mathrm{al}^{23}$ found a progressive increase in drug delivery from a pressurized metered-dose inhaler with increasing $\mathrm{V}_{\mathrm{T}}$ from 100 to $800 \mathrm{~mL}$. In contrast, Berlinski and Willis ${ }^{13}$ reported that changing the $V_{T}$ setting in a pediatric ventilator model from 100 to $200 \mathrm{~mL}$ did not increase drug delivery via IPV or jet nebulizer. However,

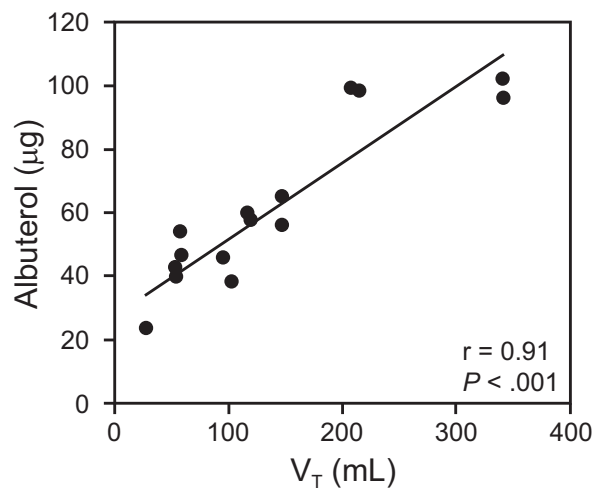

Fig. 4. Relationship between tidal volume $\left(\mathrm{V}_{\mathrm{T}}\right)$ and albuterol delivery.

the relationship between drug delivery and $\mathrm{V}_{\mathrm{T}}$ differed, depending on the position of IPV in the ventilator circuit. When IPV was placed at the humidifier (distal from the lung model), drug delivery to the lung model increased by $\sim 50 \%$ with 
increasing $\mathrm{V}_{\mathrm{T}}$, although the amount of albuterol delivered was markedly lower with IPV at the humidifier than that at the Y-piece (proximal to the lung model). ${ }^{13}$ Although it seems likely that both $\mathrm{V}_{\mathrm{T}}$ and the distance between the aerosol generator and the lung model influences drug delivery via IPV, neither $\mathrm{V}_{\mathrm{T}}$ nor the distance affects drug delivery with a jet nebulizer. ${ }^{13}$ Thus, there is a complex relationship between drug delivery and $\mathrm{V}_{\mathrm{T}}$. In our study, concomitant increases of $\mathrm{V}_{\mathrm{T}}$ and albuterol delivery were observed via IPV alone, which indicated that the IPV settings of frequency and operational pressure that improved albuterol delivery were effective in ventilation as well.

Only a small fraction of nebulized albuterol was emitted from the IPV device (Fig. 1B), as previously described. ${ }^{26}$ The aerosolized drug from the sliding venturi may be further deposited within the ETT and the trachea model, possibly due to turbulent flow (Fig. 1A and B). ${ }^{27}$ Thus, it seemed likely that the majority of albuterol remained inside the IPV device and was expelled from the ventilator (Fig. 1C). However, the efficiency of albuterol delivery in the study by Berlinski and Willis ${ }^{13}$ was 2 times higher (4\%) than that in our study when IPV was placed at the Y-piece. Because the mechanical ventilation in their study provided $\mathrm{V}_{\mathrm{T}}$ of $100 \mathrm{~mL}$ or $200 \mathrm{~mL}$ at 20 breaths $/ \mathrm{min}$, the inspiratory flow from it may contribute to the drug delivery. ${ }^{13}$ In addition, the sliding venturi was different in that the ventilator was closed in their study and open in our study (see supplementary Fig. 4 at http://www.rcjournal.com). The presence or absence of the ventilator cap on the Phasitron housing may also influence the efficiency of drug delivery because a substantial amount of albuterol was expelled from the ventilator (Fig. 1C). When considering these differences in the experimental setup, the efficiency in albuterol delivery could not be directly compared between these 2 studies. ${ }^{13}$ Thus, it would be of interest to study the efficiency of drug delivery by the combination of mechanical ventilation settings with IPV settings based on the current study.

The clinical efficacy of albuterol delivery via IPV as conducted in this in vitro study was previously described for airway clearance in subjects with atelectasis or asthma on mechanical ventilation. ${ }^{14,15}$ The drug delivery via IPV involves the removal of the ventilator circuit tubing from the ETT adapter and the attachment of the IPV device's tubing to the ETT adapter, then albuterol is administered by inhalation during IPV for 10-20 min. Recently, the IPV treatment has also been performed to improve the viability and availability of lungs of brain-dead organ donors for lung transplantation. ${ }^{28,29} \mathrm{~A}$ study by Deakins and Chatburn ${ }^{14}$ used IPV settings at frequencies that ranged from 180 to 220 cycles/min and operational pressure equal to $15-30 \mathrm{~cm} \mathrm{H}_{2} \mathrm{O}$ of the peak pressure for albuterol delivery in pediatric subjects with atelectasis. Results of our study suggested decreasing frequency to $\sim 100$ cycles $/ \mathrm{min}$ and increasing operational pressure to improve drug delivery, irrespective of $C_{L}$. Importantly, it was reported that pulmonary congestion occurred after $20 \mathrm{~min}$ in healthy lungs of a rat ventilated at $45 \mathrm{~cm} \mathrm{H}_{2} \mathrm{O}$ of PIP. ${ }^{30}$ Therefore, it is necessary to carefully maintain the airway plateau pressure $<30 \mathrm{~cm} \mathrm{H}_{2} \mathrm{O}$ during IPV for prevention of lung injury in patients with elevated $\mathrm{R}_{\mathrm{aw}} \cdot{ }^{31,32}$ Further in vivo studies on optimization of IPV parameter settings are needed for safe and effective IPV therapy in various lung diseases.

\section{Limitation}

This study was an in vitro experiment and could not be extrapolated to humans without caution because trachea and lung models mimic human lungs imperfectly. Although IPV may be superimposed on a conventional ventilator, ${ }^{33}$ this study did not consider the use of such ventilators to address the influence of the setting parameters of IPV alone on drug delivery and exclude potential influence of mechanical ventilation-related factors on drug delivery. ${ }^{13,34,35}$

\section{Conclusions}

We investigated the variations in the efficiency of drug delivery and the intrapulmonary effects with differential IPV parameter settings and lung mechanics. We showed that decreasing percussion frequency can increase drug delivery and $\mathrm{V}_{\mathrm{T}}$. $\mathrm{R}_{\mathrm{aw}}$ had a negative impact on drug delivery, whereas $\mathrm{C}_{\mathrm{L}}$ had no significant influence. Effective parameter settings for albuterol delivery were the hard mode (lower frequency) and 20 or 40 psi of operational pressure. Because high operational pressure may result in excessive PIP gain, depending on $\mathrm{R}_{\mathrm{aw}}$, it is important to monitor PIP with extreme caution in patients with high $\mathrm{R}_{\mathrm{aw}}$.

\section{REFERENCES}

1. Lucangelo U, Antonaglia V, Zin WA, Fontanesi L, Peratoner A, Bird FM, Gullo A. Effects of mechanical load on flow, volume and pressure delivered by high-frequency percussive ventilation. Respir Physiol Neurobiol 2004;142(1):81-91.

2. Bott J, Blumenthal S, Buxton M, Ellum S, Falconer C, Garrod R, et al.; British Thoracic Society Physiotherapy Guideline Development Group. Guidelines for the physiotherapy management of the adult, medical, spontaneously breathing patient. Thorax 2009;64 Suppl 1:i1-51.

3. Vargas F, Bui HN, Boyer A, Salmi LR, Gbikpi-Benissan G, Guenard $\mathrm{H}$, et al. Intrapulmonary percussive ventilation in acute exacerbations of COPD patients with mild respiratory acidosis: a randomized controlled trial [ISRCTN17802078]. Crit Care 2005;9(4):R382-389.

4. Nava S, Barbarito N, Piaggi G, De Mattia E, Cirio S. Physiological response to intrapulmonary percussive ventilation in stable COPD patients. Respir Med 2006;100(9):1526-1533. 


\section{Variations in Albuterol Delivery With IPV Settings}

5. Vargas F, Boyer A, Bui HN, Guenard H, Gruson D, Hilbert G. Effect of intrapulmonary percussive ventilation on expiratory flow limitation in chronic obstructive pulmonary disease patients. J Crit Care 2009;24(2):212-219.

6. Testa A, Galeri S, Villafañe JH, Corbellini C, Pillastrini P, Negrini $\mathrm{S}$. Efficacy of short-term intrapulmonary percussive ventilation in patients with chronic obstructive pulmonary disease. Disabil Rehabil 2015;37(10):899-903.

7. Toussaint M, De Win H, Steens M, Soudon P. Effect of intrapulmonary percussive ventilation on mucus clearance in duchenne muscular dystrophy patients: a preliminary report. Respir Care 2003; 48(10):940-947.

8. Paneroni M, Clini E, Simonelli C, Bianchi L, Degli Antoni F, Vitacca M. Safety and efficacy of short-term intrapulmonary percussive ventilation in patients with bronchiectasis. Respir Care 2011; 56(7):984-988.

9. Newhouse PA, White F, Marks JH, Homnick DN. The intrapulmonary percussive ventilator and flutter device compared to standard chest physiotherapy in patients with cystic fibrosis. Clin Pediatr (Phila) 1998;37(7):427-432.

10. Varekojis SM, Douce FH, Flucke RL, Filbrun DA, Tice JS, McCoy KS, Castile RG. A comparison of the therapeutic effectiveness of and preference for postural drainage and percussion, intrapulmonary percussive ventilation, and high-frequency chest wall compression in hospitalized cystic fibrosis patients. Respir Care 2003;48(1):24-28.

11. Toussaint M, Guillet MC, Paternotte S, Soudon P, Haan J. Intrapulmonary effects of setting parameters in portable intrapulmonary percussive ventilation devices. Respir Care 2012;57(5):735-742.

12. Reychler G, Wallemacq P, Rodenstein DO, Cumps J, Leal T, Liistro G. Comparison of lung deposition of amikacin by intrapulmonary percussive ventilation and jet nebulization by urinary monitoring. $\mathrm{J}$ Aerosol Med 2006;19(2):199-207.

13. Berlinski A, Willis JR. Albuterol delivery via intrapulmonary percussive ventilator and jet nebulizer in a pediatric ventilator model. Respir Care 2010;55(12):1699-1704.

14. Deakins K, Chatburn RL. A comparison of intrapulmonary percussive ventilation and conventional chest physiotherapy for the treatment of atelectasis in the pediatric patient. Respir Care 2002;47(10): 1162-1167.

15. Morita M, Kondo T, Takahashi T. A pediatric case of life-threatening asthma managed with sevoflurane, intrapulmonary percussive ventilation and prone positioning. J Jpn Soc Intensive Care Med 2015;22:199-201. Available at https://www.jstage.jst.go.jp/article/ jsicm/22/3/22_199/_pdf/-char/ja.

16. Berlinski A, Waldrep JC. Four hours of continuous albuterol nebulization. Chest 1998;114(3):847-853.

17. Frank NR, Mead J, Ferris BG Jr. The mechanical behavior of the lungs in healthy elderly persons. J Clin Invest 1957;36(12):16801687.

18. Don HF, Robson JG. The mechanics of the respiratory system during anesthesia. The effects of atropine and carbon dioxide. Anesthesiology 1965;26:168-178.

19. Broseghini C, Brandolese R, Poggi R, Polese G, Manzin E, MilicEmili J, Rossi A. Respiratory mechanics during the first day of mechanical ventilation in patients with pulmonary edema and chronic airway obstruction. Am Rev Respir Dis 1988;138(2):355-361.

20. Kondili E, Prinianakis G, Anastasaki M, Georgopoulos D. Acute effects of ventilator settings on respiratory motor output in patients with acute lung injury. Intensive Care Med 2001;27(7):1147-1157.

21. Fink JB. Aerosol delivery to ventilated infant and pediatric patients. Respir Care 2004;49(6):653-665.

22. Everard ML, Stammers J, Hardy JG, Milner AD. New aerosol delivery system for neonatal ventilator circuits. Arch Dis Child 1992; 67(7 Spec No):826-830.

23. Fink JB, Dhand R, Duarte AG, Jenne JW, Tobin MJ. Aerosol delivery from a metered-dose inhaler during mechanical ventilation. An in vitro model. Am J Respir Crit Care Med 1996;154(2 Pt 1): 382-387.

24. Berlinski A, Willis JR. Effect of tidal volume and nebulizer type and position on albuterol delivery in a pediatric model of mechanical ventilation. Respir Care 2015;60(10):1424-1430.

25. O'Riordan TG, Greco MJ, Perry RJ, Smaldone GC. Nebulizer function during mechanical ventilation. Am Rev Respir Dis 1992;145(5): $1117-1122$

26. Reychler G, Keyeux A, Cremers C, Veriter C, Rodenstein DO, Liistro G. Comparison of lung deposition in two types of nebulization: intrapulmonary percussive ventilation vs jet nebulization. Chest 2004; 125(2):502-508.

27. Dekker E. Transition between laminar and turbulent flow in human trachea. J Appl Physiol 1961;16:1060-1064.

28. Lerg G, Shanta L. Intrapulmonary percussive ventilation as a lung recruitment strategy in brain-dead organ donors. Prog Transplant 2017;27(1):84-89.

29. Chang SH, Kreisel D, Marklin GF, Cook L, Hachem R, Kozower $\mathrm{BD}$, et al. Lung focused resuscitation at a specialized donor care facility improves lung procurement rates. Ann Thorac Surg 2018; 105(5):1531-1536.

30. Dreyfuss D, Saumon G. Ventilator-induced lung injury: lessons from experimental studies. Am J Respir Crit Care Med 1998;157(1):294323

31. Acute Respiratory Distress Syndrome Network, Brower RG, Matthay MA, Morris A, Schoenfeld D, Thompson BT, Wheeler A. Ventilation with lower tidal volumes as compared with traditional tidal volumes for acute lung injury and the acute respiratory distress syndrome. N Engl J Med 2000;342(18):1301-1308.

32. Malhotra A. Low-tidal-volume ventilation in the acute respiratory distress syndrome. N Engl J Med 2007;357(11):1113-1120.

33. Tsuruta R, Kasaoka S, Okabayashi K, Maekawa T. Efficacy and safety of intrapulmonary percussive ventilation superimposed on conventional ventilation in obese patients with compression atelectasis. J Crit Care 2006;21(4):328-332.

34. Dhand R. Aerosol delivery during mechanical ventilation: from basic techniques to new devices. J Aerosol Med Pulm Drug Deliv 2008; 21(1):45-60.

35. Kallet RH. Adjunct therapies during mechanical ventilation: airway clearance techniques, therapeutic aerosols, and gases. Respir Care 2013;58(6):1053-1073

This article is approved for Continuing Respiratory Care Education credit. For information and to obtain your CRCE

(free to AARC members) visit www.rcjournal.com

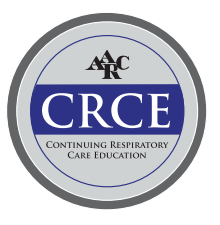

